\title{
HAM/TSP: association between white matter lesions on magnetic resonance imaging, clinical and cerebrospinal fluid findings
}

\author{
HAM/TSP: associação entre lesões de substância branca à ressonância magnética, \\ achados clínicos e do líquido cefalorraquidiano \\ Marzia Puccioni-Sohler¹, Emerson Gasparetto², Mauro Jorge Cabral-Castro ${ }^{3}$, Carla Slatter ${ }^{4}$, Cecilia M. Vidal', \\ Romeu Domingues Cortes ${ }^{6}$, Bruce R. Rosen7, Caterina Mainero ${ }^{8}$
}

\begin{abstract}
Objective:Toinvestigatetheassociation betweenclinicaldata, whitematterlesionsand inflammatorycerebrospinalfluid(CSF)findingsin HTLV-1 associated myelopathy/tropical spastic paraparesis (HAM/TSP). Method:We studied brain and cervical spinal cord on magnetic resonance imaging (MRI) and CSF examinations of 28 Brazilian HAM/TSP patients. Results: The majority of patients had severe neurological incapacity with EDSS median of6.5 (3-8). The brain MRI showed white matter lesions (75\%) and atrophy (14\%). The preferential brain location was periventricular. Cervical demyelination lesions occurred in $11 \%$ of the cases, and cervical atrophy in 3.5\%. One patient had enhancement lesions on T1 cervical spinal cord MRI.Cases with spinal cord lesions had signs of acuteCSFinflammation. The brain white matter lesions predominated in the patients with higher age.Conclusion:Our data suggest that an active inflammatory process is associated with the cervical spinal cord lesions in HAM/TSP. The brain abnormalities are not related to the clinical picture of HAM/TSP.
\end{abstract}

Key words: human T-lymphotropic virus 1, HTLV-1 associated myelopathy, cerebrospinal fluid, magnetic resonance imaging.

RESUMO

Objetivo: Analisar a associação entre aspectos clínicos, lesões de substância branca e reação inflamatória aguda no líquido cefalorraquidiano (LCR) na mielopatia associa ao HTLV-1 (HAM/TSP). Método: Foram estudadas ressonâncias magnéticas (RM) do encéfalo/medula espinhal cervical e exame do LCR de 28 pacientes com HAM/TSP. Resultados: A maioria dos pacientes apresentava grave incapacidade neurológica, com EDSS 6,5 (3-8). A RM revelou lesões da substância branca (75\%) com predominância periventricular e atrofia cortical (14\%). Lesões desmielinizantes cervicais ocorreram em $11 \%$ dos casos e atrofia em 3,5\%. Um paciente apresentou lesão cervical na T1 com captação de contraste. Sinais de inflamação aguda no LCR ocorreram em situações de lesão da medula espinhal cervical. As alterações de substância branca do encéfalo predominaram nos indivíduos com maior faixa etária. Conclusão: Nossos achados sugerem que processo inflamatório com atividade clínica na HAM/TSP está associado a lesões da medula espinhal cervical. As anormalidades da substância branca encefálicas não são relacionadas ao quadro clínico de HAM/TSP.

Palavras-Chave: vírus linfotrópico de células T humanas tipo 1, mielopatia associa ao HTLV-1, líquido cefalorraquidiano, imagem por ressonância magnética.

Human T-cell lymphotropic virus type 1 (HTLV-1) was the first retrovirus to be isolated in humans ${ }^{1}$. It is endemic in southeastern Japan, the Caribbean, South America and parts of Africa, and also in Melanesia and the Middle East ${ }^{2}$. There are approximately 20 million people infected worldwide ${ }^{3,4}$.
Most infected patients remain asymptomatic. Approximately 1-2\% develop a chronic spastic paraparesis called as HTLV-1 associated myelopathy/tropical spastic paraparesis (HAM/ TSP). It predominantly involves the spinal cord at the thoracic level. Laboratory diagnosis is based on the demonstration

\footnotetext{
${ }^{1}$ Professor and Chief, Clinical Pathology Service/Cerebrospinal Fluid Laboratory, University Hospital Clementino Fraga Filho of the Federal University of Rio de Janeiro (HUCFF/UFRJ), Rio de Janeiro RJ, Brazil, and Cerebrospinal Fluid Laboratory Neurolife and Neuroinfection Clinic, University Hospital Graffrée e Guinle of the Federal University of the State of Rio de Janeiro (HUGG/ UNIRIO), Rio de Janeiro RJ, Brazil;

2 Professor and Radiologist, Center for Imaging Diagnosis (CDPI), Rio de Janeiro RJ, Brazil;

${ }^{3}$ Microbiologist, Clinical Pathology Service/Cerebrospinal Fluid Laboratory, HUCFF/UFRJ, and Institute of Microbiology Paulo de Góes, UFRJ, Rio de Janeiro RJ, Brazil; ${ }^{4}$ Neurologist, Neuroinfection Clinic, HUGG/ UNIRIO, Rio de Janeiro RJ, Brazil;

${ }^{5}$ Medical Student, Neuroinfection Clinic, HUGG/ UNIRIO, Rio de Janeiro RJ, Brazil;

${ }^{6}$ Director and Radiologist, CDPI, Rio de Janeiro RJ, Brazil;

${ }^{7}$ Professor and Director of the Athinoula A. Martinos Center Harvard Medical School, Boston, USA;

${ }^{8}$ Assistant in Neuroscience, Harvard Medical School, Boston, USA.

Correspondence: Marzia Puccioni-Sohler; Praia do Flamengo 66 / Bloco B / conj. 219-220; 22210-903 Rio de Janeiro RJ - Brasil; Email: mpuccioni@hucff.ufrj.br Support: Fundação de Amparo à Pesquisa do Rio de Janeiro (FAPERJ), Brazil, and National Institutes of Health, USA.

Conflict of interest: There is no conflict of interest to declare.
}

Received 07 September 2011; Received in final form 25 November 201; Accepted 02 December 2011 
of anti-HTLV-1 antibodies in serum and cerebrospinal fluid $(\mathrm{CSF})^{5-7}$.

Inflammatory CSF occurs in 95\% of cases of HAM/TSP. Pleocytosis, high protein concentration and dysfunction of blood-CSF barrier are cardinal signs of an acute inflammatory process ${ }^{8}$. Among the chronic inflammatory parameters, intrathecal synthesis of immunoglobulins (total and antiHTLV-1IgG) remains stable throughout the disease9.

Studies of magnetic resonance image (MRI) demonstrate atrophy, focal lesions and diffuse white matter abnormalities in the spinal cord and more discrete in brain of HAM/TSP patients ${ }^{10}$. The pathogenic and clinical significance of the brain lesions is not completely understood. The abnormalities could be due to the inflammatory process induced by viruses, such as occurs in spinal cord, or represent lacunar infarctions associated with degenerative microangiopathy, characteristic of the predominant age group in patients ${ }^{11}$.

The investigation of the association between clinical findings, the CSF and imaging was performed to clarify the significance of white matter lesions found on MRI in patients with HAM/TSP.

\section{METHODS}

This descriptive and prospective study included 28 cases of $\mathrm{HAM} / \mathrm{TSP}^{7}$, seen in the Neuroinfection Outpatient Clinic of the University Hospital Graffrée e Guinle of the Federal University of the State of Rio de Janeiro (HUGG/UNIRIO) for the period between August 2006 and August 2011. All patients underwent MRI of the brain, cervical spine and CSF analysis. The Kurtzke Expanded Disability Status Scale (EDSS) was used to grade the severity of the neurological incapacity ${ }^{12}$. Normal neurological examination in the EDSS corresponded to zero, while the progression to death was represented by 10. All patients had positive serum and CSF for HTLV-1 determined by enzyme-linked immunosorbent assay (ELISA) (ADALTIS, FDA, Montreal, Quebec), confirmed by Western blot in serum (Diagnostic Biotechnology, Singapore City, Singapore). The presence of cerebrovascular disease was excluded. The study was approved by the Ethics in Research of HUGG/Ministry of Health. All patients signed a consent form.

\section{CSF analysis}

It includes cytology, assessment of the total protein concentration and CSF glucose, albumin and IgG in paired CSF and serum by nephelometric method (Dade Behring), and oligoclonal IgG bands in the CSF and serum by isoelectric focusing method (Pharmacia). The albumin quotient (CSF/ serum) assessed the presence of dysfunction of the bloodCSF barrier $\left(\mathrm{Q}\right.$ alb $\geq 8 \times 10^{-3}$ ), whereas the $\operatorname{IgG}$ index ( $\mathrm{Q} \operatorname{IgG} / \mathrm{Q}$ albumin) $\geq 0.7$ and/or detection oligoclonal $\operatorname{IgG}$ bands in CSF showed intrathecal synthesis of total $\operatorname{IgG}^{13}$. We used the specific antibody index (AI) to determine the intrathecal synthesis of anti-HTLV-1 $(\mathrm{AI} \geq 1.5)^{14,15}$.

\section{MRI findings}

The patients underwent brain and cervical spinal cord on a 3.0 Tesla scanner (TIM Trio, Siemens, Germany) with the following protocol: 1) brain - sagital T1-weighted images, coronal T2-weighted images, axial FLAIR sequence, axial diffusion-weighted images and axial T1-weighted images after intravenous injection of gadolinium; 2) spinal cord - sagittal T1- and T2-weighted images, axial T2*-weighted images and axial T1-weighted images post-gadolinium administration. Two board certified radiologists evaluated the images and defined the following findings by consensus: presence of white matter T2 hyperintense lesions and its distribution, and presence of indirect signal of brain (proeminence of cortical sulci and fissures, and ventricular enlargement) and spinal cord (diameter reduction) atrophy.

\section{Statistical analysis}

It included the Mann-Whitney test to compare numeric data between two subgroups and the Fisher exact test to compare categorical data. The level of significance was $5 \%$.

\section{RESULTS}

Characteristics of patients with HAM/TSP - The group of 28 patients with HAM/TSP was predominantly composed by females (2:1); median age: 54 years (range, 35-74 years); median disease duration: 9.5 years (range, 1-28 years). The majority of patients (79\%) reported five or more years of symptoms. All patients required support to walk and $46 \%$ of them were confined to a wheelchair. The median EDSS was 6.5 (constant bilateral assistance required to walk about 20 meters without resting), ranging from 3 (fully ambulatory) to 8 (restricted to wheelchair). The onset and progression of disease were bimodal: six patients had an abrupt onset with rapid progression ( $<5$ years) to severe neurological disability (four paraplegics confined to a wheelchair and two paraparetic, requiring support). In the remaining 22 patients, the beginning was insidious with chronic evolution.

CSF analysis - Abnormal test occurred in $96.5 \%$ of the patients with HAM/TSP: 7\% had protein isolated high level of protein in CSF, and $89 \%$ had inflammatory reaction in CSF. The association between the variables showed that patients with cardinal signs of an acute inflammatory process, such as pleocytosis, had similar duration of symptoms compared to the group with intrathecal synthesis of total IgG and anti-HTLV-1 (Table 1). There was no association between CSF findings, patient age and disability.

MRI findings - Cerebral white matter abnormalities were seen on the T2-weighted images of the brain in $75 \%$ of the patients, with periventricular preferred location (Fig 1). 
Table 1. Association between CSF findings and clinical aspects of 28 HAM/TSP patients.

\begin{tabular}{|c|c|c|c|c|c|}
\hline & $\begin{array}{l}\text { Pleocytosis } \\
\left(>4 \text { cells } / \mathrm{mm}^{3}\right)\end{array}$ & $\begin{array}{l}\text { Proteins } \\
\text { (>40 mg/dL) }\end{array}$ & $\begin{array}{l}\text { Albumin quotient } \\
\qquad\left(\geq 8 \times 10^{-3}\right)\end{array}$ & $\begin{array}{c}\text { IgG index } \\
(\geq 0.7) \\
\text { and/or OB }\end{array}$ & $\begin{array}{c}\text { Al } \\
\text { HTLV-1 } \\
(\geq 1.5)\end{array}$ \\
\hline $\mathrm{HAM} / \mathrm{TSP}$ & $\begin{array}{l}18 / 28 \\
(64 \%)\end{array}$ & $\begin{array}{l}15 / 28 \\
(54 \%)\end{array}$ & $\begin{array}{l}7 / 28 \\
(25 \%)\end{array}$ & $\begin{array}{l}20 / 28 \\
(71 \%)\end{array}$ & $\begin{array}{l}22 / 28 \\
(79 \%)\end{array}$ \\
\hline $\begin{array}{l}\text { Median age } \\
\text { (Variation) }\end{array}$ & $\begin{array}{c}52 \\
(35-74)\end{array}$ & $\begin{array}{c}56 \\
(40-74)\end{array}$ & $\begin{array}{c}52 \\
(40-74)\end{array}$ & $\begin{array}{c}55.5 \\
(35-74)\end{array}$ & $\begin{array}{c}53 \\
(35-74)\end{array}$ \\
\hline $\begin{array}{l}\text { TS in years Median } \\
\text { (Variation) }\end{array}$ & $\begin{array}{c}9.5 \\
(1-21)\end{array}$ & $\begin{array}{c}6 \\
(1-18)\end{array}$ & $\begin{array}{c}4 \\
(1-11)\end{array}$ & $\begin{array}{c}10 \\
(1-28)\end{array}$ & $\begin{array}{c}8.5 \\
(1-28)\end{array}$ \\
\hline $\begin{array}{l}\text { EDSS Median } \\
\text { (Variation) }\end{array}$ & $\begin{array}{c}7 \\
(3-8) \\
\end{array}$ & $\begin{array}{c}6 \\
(3-8) \\
\end{array}$ & $\begin{array}{c}7 \\
(4.5-8) \\
\end{array}$ & $\begin{array}{c}6.5 \\
(4.5-8) \\
\end{array}$ & $\begin{array}{l}6.25 \\
(3-8) \\
\end{array}$ \\
\hline
\end{tabular}

TS:Time of symptoms; EDSS: Expanded Disability Status Scale; OB: Oligoclonal band; Al: Specific antibody index; HTLV-1: Human T-cell lymphotropic virus type 1; HAM/TSP: HTLV-1 associated myelopathy/tropical spastic paraparesis; CSF: cerebrospinal fluid.
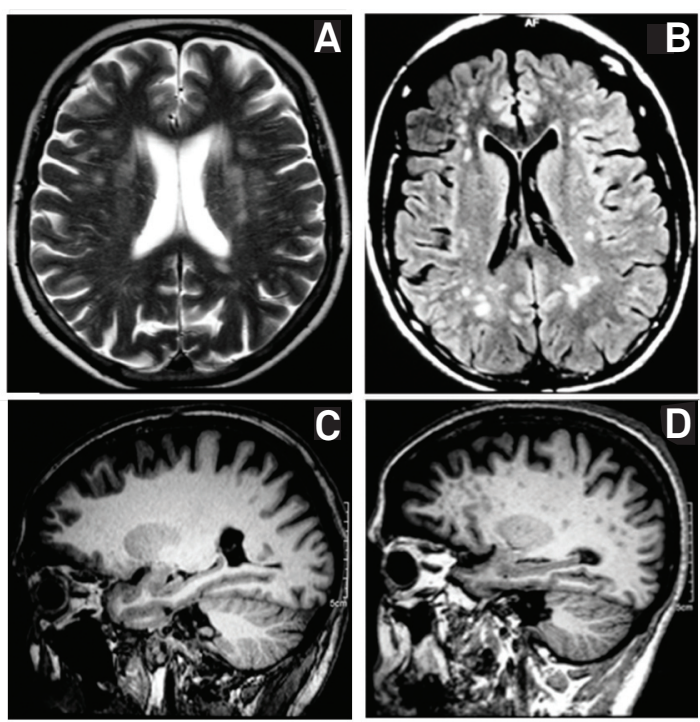

Fig 1. Brain MRI findings in HTLV-1 infection. (A) Axial T2weighted image shows multiple foci of high signal intensity on the white matter, mainly in the periventricular region. (B) Axial FLAIR demonstrates a similar pattern of high signal intensity foci, predominating in the subcortical region. (C) Sagittal T1-weighted image shows no significant abnormalities. (D) Sagittal T1-weighted image demonstrates multiple foci of low signal intensity in the white matter.

Signs of brain atrophy (prominence of cortical sulci and fissures, and ventricular enlargement) occurred in four patients, three of them with concomitant white matter lesions. One of them had pronounced atrophy in the convexity, particularly in the frontal regions, as well in the cisternas and sylvian fissures. Another patient had cerebellar atrophy associated with slight accentuation of cisternas. Regarding MRI of the cervical spinal cord, hyperintense lesions were found in three patients (11\%). One of them had hyperintense signal with contrast enhancement. Spinal cord atrophy was found in only one case, characterized by thinning of the cervical spine and the proximal portion of the dorsal medulla (Fig 2).

A significant association was found between the presence of cerebral white matter lesions and periventricular location with older patients, as well as between periventricular location and absence of acute signs of inflammation in CSF (pleocytosis, protein concentration and dysfunction of blood-CSF barrier) (Tables 2 and 3). There was no association between other brain locations, duration of symptoms and disability (Table 2). No patients had brain gadolinium enhancement lesions. Spinal cord hyperintense lesions in the white substance of the cervical spine occurred in three paraplegic patients, all confined to a wheelchair: 1. MJRS, 66 years old, 18 years of disease, had acute inflammatory CSF (pleocytosis, high protein concentration and intrathecal synthesis of total $\operatorname{IgG}$ ), and MRI revealed multiple foci of hyperintensity on T2 diffusely involving the cervical spine; 2 . MRI, 40 years old, one year of illness, presented CSF pleocytosis with $\left(17 \mathrm{cells} / \mathrm{mm}^{3}\right)$ high protein concentration $(84 \mathrm{mg} / \mathrm{dl})$, dysfunction of blood-CSF barrier $\left(14.7 \times 10^{-3}\right)$ and intrathecal synthesis of HTLV-1 antibodies (73.3), MRI image showed an oval hyperintense signal on STIR with contrast enhancement, measuring about $5 \mathrm{~mm}$ in diameter in the earlier portions of the cervical cord at C1 (Fig 2); 3. MDT, 54 years old, 24 years of disease, normal CSF examination, MRI showed hyperintense signal on T2 images in the C4-C5-C6-C7 associated with atrophy of the cervical spinal cord. Only the patient 2 had gadolinium enhancement in the cervical spinal cord in MRI.

\section{DISCUSSION}

Changes in MRI of the brain and spinal cord have been found in patients with $\mathrm{HAM} / \mathrm{TSP}^{10}$. In sense to clarify the origin of and the significance of these lesions, we studied the brain and spinal cord MRI of $28 \mathrm{HAM} / \mathrm{TSP}$ patients? ${ }^{7}$ We compared the MRI findings with clinical and CSF finding. In the whole patients group studied, $75 \%$ of subjects had hyperintense lesions in brain white matter ( $50 \%$ periventricular) and $11 \%$, spinal cord. Indirect signals of atrophy were observed in $14 \%$ of MRI of the brain and only $3 \%$ of the spinal cord. The frequency of these changes has been variable in the literature: hyperintense lesions in brain (52.4\% -84\%) and in spinal cord $(7.9 \%)^{16-20}$. Atrophy of the spinal cord occurred in $20-74 \%$ of the cases. These differences may be due to individual characteristics of the population, such as age, 

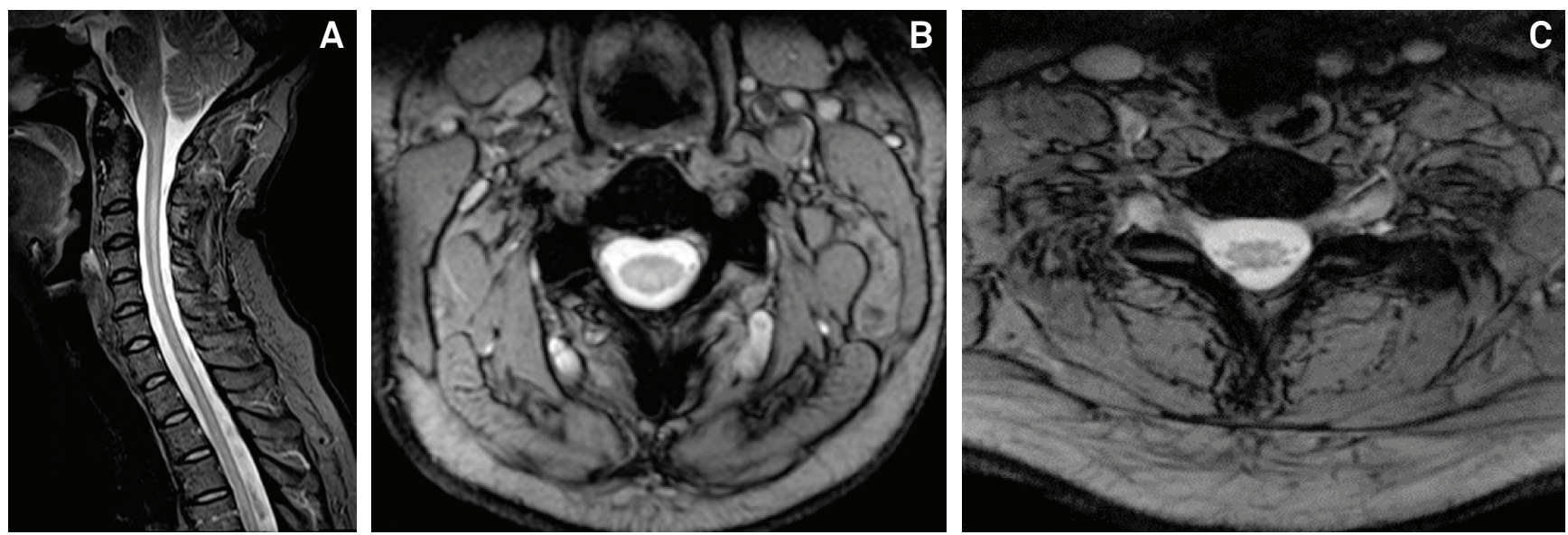

Fig 2. Cervical spinal cord MRI findings in HTLV-1 infection. (A) Sagittal STIR and (B) axial T2* GRE (at the level of C3) demonstrate extensive high signal intensity from C2 to the level of the dorsal spinal cord, predominating on the posterior region of the spinal cord, as well as mild spinal cord atrophy. (C) Axial T2* GRE (at the level of D3) shows the spinal cord atrophy and diffuse high signal intensity.

sex, degree of neurological disability, degree of disease progression and duration of symptoms. We observed association between the age and the frequency of $\mathrm{T} 2$ hyperintense brain MRI lesions, but not with disease duration, disability and CSF findings. Based on our data, we speculate whether the brain MRI T2 hyperintense lesions could be related with a microdegenerative process associated to the age. Additionally, the presence of acute inflammatory CSF (pleocytosis, high concentration of protein and blood-CSF barrier dysfunction) was found in patients with MRI T2 hyperintense cervical lesions. Interesting, this location is closest to the CSF space and may reflect the cervical cord inflammatory lesion

Neurologic disability was severe in our population. All of them depended on support to walk or were confined to wheelchairs, with a median duration of symptoms of 9.5 years (1-28 years). Gessain and Gout reported that, about 10 years after onset of symptoms, $30 \%$ of patients were confined to bed and $45 \%$ needed assistance to walk ${ }^{21}$. There was variability of the clinical forms: rapidly progressive evolution to severe disability in six patients with $<5$ years of symptoms and chronic forms. The progression of acute symptoms could reflect a marked inflammatory process that occurs in the spinal cord ${ }^{22}$. Despite the bimodal progression observed in our population of HAM /TSP, there was no significant association between the degree of disability assessed by EDSS and duration of symptoms and findings of brain MRI. One out of six patients with rapidly evolving had enhancement lesion in MRI of the cervical spine and signs of acute inflammation in CSF. This is considered by some authors a malignant form, variant HAM/TSP. Anatomopathological findings appear to be associated with the duration of the myelopathy, in which shorter length of illness is associated with marked inflammation in the spinal cord, whereas predominance of degeneration occurs in patients with more than nine years of illness. The coexistence of chronic and active lesions is described in the intermediate period of symptoms ${ }^{22}$.
The CSF examination revealed the inflammatory origin of this disease in $89 \%$ of patients, consistent with the literature $(95 \%)^{13,15}$. There was a higher frequency of acute signs of inflammation characterized by pleocytosis (64\%) compared to previous studies $(26 \%)^{15}$. This is in agreement with the clinical findings of severe outcome. In general, patients with signs of acute inflammation in the CSF had a shorter duration of symptoms [median, 6.5 years (1-21 years)]. By definition, it is speculated that, despite the chronic disease, could have occurred reactivation of inflammatory signs of disease activity. Similar to this situation, Iwasaki et al. reported anatomical and pathological changes of active inflammatory lesions in the spinal cord in a case of HAM/TSP with 29 years of disease ${ }^{23}$.

Morgan et al. observed no differences between the number, size and location of lesions in patients with HAM/TSP and seropositive controls ${ }^{19}$. The authors found no correlation between volume and number of lesions and clinical characteristics of patients, EDSS, viral load in peripheral blood and production of gamma-globulin. These suggested that the high frequency of abnormalities in white matter in patients infected with HTLV-1 is related to the early presence of inflammation of the central nervous system. However, as patients were matched by the same age, the high frequency of white matter lesions on MRI in both groups could be related to demyelination secondary to degenerative microangiopathy. Kira et al. and Ogata et al. demonstrated, through MRI and autopsy, correlation between the periventricular white matter lesions and cerebral spinal posterior column ${ }^{24,25}$. The study revealed similar pathologic changes to the brain and spinal cord, with demyelination, loss of axons and thickening of small vessels. The authors explained the absence of inflammatory infiltration by the use of corticosteroids. However, autopsy studies show that inflammatory changes are perivascular infiltration, rarely occurred activated $\mathrm{T}$ lymphocytes, as well as damage in the parenchyma ${ }^{25}$. In this study, no significant associations 
between the presence and location of white matter lesions on brain MRI and duration of illness or disability were found. Nevertheless, we identified an association between older age and the findings of brain MRI, and the periventricular location and no signs of acute inflammation in CSF.

Cerebral atrophy was observed in $14 \%$ of our patients with HAM/TSP. In the study by Griffith et al., only 5\% (1/19) patients with HAM/TSP had cerebral atrophy, showing that this is not frequent, although the authors suggest that

Table 2. Association between white matter lesions of the brain with clinical findings in 28 HAM/TSP patients.

\begin{tabular}{|c|c|c|c|}
\hline Variable & $\begin{array}{l}\text { White matter lesions } \\
\text { (T2) }\end{array}$ & Median (range) & $\mathrm{p}$-value \\
\hline \multirow{2}{*}{ AGE } & $\operatorname{Pos}(21)$ & $56(40-74)$ & \multirow{2}{*}{$<0.05$} \\
\hline & $\operatorname{Neg}(7)$ & $49(35-55)$ & \\
\hline \multirow{2}{*}{ TS (yrs.) } & Pos (21) & $8(1-28)$ & \multirow{2}{*}{$>0.05$} \\
\hline & $\operatorname{Neg}(7)$ & $16(4-21)$ & \\
\hline \multirow[b]{2}{*}{ EDSS } & Pos (21) & $7(3-8)$ & \multirow{2}{*}{$>0.05$} \\
\hline & $\operatorname{Neg}(7)$ & $6.5(3-7)$ & \\
\hline Variable & Periventricular lesions & & \\
\hline \multirow{2}{*}{ AGE } & Pos $(14)$ & $59(40-74)$ & \multirow{2}{*}{$<0.05$} \\
\hline & Neg (14) & $49(35-66)$ & \\
\hline \multirow{2}{*}{ TS (yrs.) } & Pos (14) & $9.5(1-28)$ & \multirow{2}{*}{$>0.05$} \\
\hline & $\operatorname{Neg}(14)$ & $10(3-21)$ & \\
\hline \multirow{2}{*}{ EDSS } & Pos (14) & $6.25(3-8)$ & \multirow{2}{*}{$>0.05$} \\
\hline & $\operatorname{Neg}(14)$ & $6.5(3-7)$ & \\
\hline Variable & Subcortical lesions & & \\
\hline \multirow{2}{*}{ AGE } & Pos (10) & $50.5(42-70)$ & \multirow{2}{*}{$>0.05$} \\
\hline & Neg (18) & $54.5(35-74)$ & \\
\hline \multirow{2}{*}{ TS (yrs.) } & Pos (10) & $6(3-14)$ & \multirow{2}{*}{$>0.05$} \\
\hline & Neg (18) & $14(1-28)$ & \\
\hline \multirow{2}{*}{ EDSS } & Pos (10) & $6.5(3-8)$ & \multirow{2}{*}{$>0.05$} \\
\hline & $\operatorname{Neg}(18)$ & $6.5(6-8)$ & \\
\hline Variable & Semioval centre & & \multirow{3}{*}{$>0.05$} \\
\hline \multirow{2}{*}{ AGE } & Pos (9) & $59(40-74)$ & \\
\hline & Neg (19) & $52(35-70)$ & \\
\hline \multirow{2}{*}{ TS (yrs.) } & Pos (9) & $8(1-18)$ & \multirow{2}{*}{$>0.05$} \\
\hline & $\operatorname{Neg}(19)$ & $13(3-28)$ & \\
\hline \multirow{2}{*}{ EDSS } & Pos (9) & $6.5(3-8)$ & \multirow{2}{*}{$>0.05$} \\
\hline & Neg (19) & $6.5(3-8)$ & \\
\hline Variable & Corona radiata & & \\
\hline \multirow{2}{*}{ AGE } & Pos (9) & $57(40-74)$ & \multirow{2}{*}{$>0.05$} \\
\hline & $\operatorname{Neg}(19)$ & $52(35-70)$ & \\
\hline \multirow{2}{*}{ TS } & Pos (9) & $8(1-24)$ & \multirow{2}{*}{$>0.05$} \\
\hline & Neg (19) & $10(3-28)$ & \\
\hline \multirow{2}{*}{ EDSS } & Pos (9) & $7(4.5-8)$ & \multirow{2}{*}{$>0.05$} \\
\hline & Neg (19) & $6(3-8)$ & \\
\hline
\end{tabular}

TS:Time of symptoms, EDSS: Expanded Disability Status Scale; HAM/TSP HTLV-1 associated myelopathy/tropical spastic paraparesis. the mechanisms of brain atrophy are the same responsible for spinal cord atrophy secondary to degeneration of the parenchyma $^{26}$.

Cervilla et al. did not show hyperintense lesions in the spinal cord of patients with HAM/TSP, but $87 \%$ had atrophy of the dorsal segment ${ }^{18}$. The median range of age of the patients consisted of 56 years (26-73), and the evolution time was 11.6 years (3-33). In the study by Bagnato et al., $14 \%$ of patients had hyperintensity on spinal cord images ${ }^{16}$. Moreover, Umehara et al. studied 11 patients with HAM/TSP with lesions in the spinal cord ${ }^{10}$. The variation in the duration of the disease consisted of three to seven months, $72 \%$ had pleocytosis and high protein concentration. MRI showed changes in the cervical, thoracic and cervico-thoracic, characterized by swelling and T2 hyperintense lesions in the posterior or lateral columns. Therefore, the authors suggest the existence of a variant of HAM/TSP and also that the changes observed on MRI would be the reflection of an early and active inflammation in the spinal cord ${ }^{27,28}$. In our series, three patients (15\%) had demyelinating lesions in cervical cord, all with the same degree of disability, paraplegic, confined to a wheelchair, but with differences in duration of illness, the CSF profile and the characteristics of image. In a patient with 18 years of symptoms, CSF examination showed signs of inflammatory activity associated with local immune reaction and multiple foci of demyelination diffusely involving the cervical spine. This is consistent with a pathologic finding of HAM/TSP, in which signs of activity appear throughout disease progression ${ }^{22}$. The other patient had only one year of illness, CSF examination showed signs of inflammatory activity, as well as MRI, showing a single image with hyperintense signal on STIR and contrast enhancement in the cervical spinal cord, consistent with the findings of early active lesions of HAM/TSP ${ }^{10}$. Finally, the third patient, with 24 years of disease, normal CSF, showed atrophy of the cervical and thoracic cord associated with hyperintense signal on T2 image at C4-C5-C6-C7 compatible with the chronic form of HAM/TSP ${ }^{22}$. An interesting aspect is that, although the population studied was found with advanced disease, there was only one case of spinal cord atrophy.

In conclusion, our findings show that the cerebral white matter lesions are nonspecific. These predominated in the middle aged or older patients. Probably, the majority of them have nothing to do with the clinical picture of HAM/TSP. The

Table 3. Association between presence and location of brain white matter lesions of brain and active inflammatory CSF findings in $28 \mathrm{HAM} / \mathrm{TSP}$ patients.

\begin{tabular}{|c|c|c|c|}
\hline Findings on Brain MRI & $\begin{array}{c}\text { Presence of pleocytosis/ } \\
\text { Hyperproteinorrachia/ Disf. Blood-CSF barrier }\end{array}$ & $\begin{array}{c}\text { Absence of pleocytosis/ } \\
\text { Hyperproteinorrachia/ Disf. Blood-CSF barrier }\end{array}$ & $p$-value \\
\hline White matter lesions & $10(67 \%)$ & $6(100 \%)$ & $>0.05$ \\
\hline Periventricular lesions & $4(27 \%)$ & $6(100 \%)$ & $<0.05$ \\
\hline Subcortical lesions & $6(40 \%)$ & 0 & $>0.05$ \\
\hline Semioval centre & $5(33 \%)$ & $1(17 \%)$ & $>0.05$ \\
\hline Corona radiata & $5(33 \%)$ & $1(17 \%)$ & $>0.05$ \\
\hline
\end{tabular}

HAM/TSP: HTLV-1 associated myelopathy/tropical spastic paraparesis; CSF: cerebrospinal fluid. 
reported lesions are similar to those found in degenerative microangiopathy. In this study, consistent with the literature, there was no association between the presence of cerebral white matter lesions with sex, disease duration and degree of neurological disability of patients with HAM/TSP. The profile of the CSF, similar to other published studies, showed an inflammatory pattern in the majority of the patients. Spinal cord lesions were associated with active inflammation in the
CSF. Moreover, signs of active and acute inflammation (linfomonuclear pleocytosis, high protein concentration and dysfunction of the blood-CSF) were associated with more severe form of HAM/TSP and shorter duration of disease. However, the presence of acute inflammatory CSF findings in patients with longer time of symptoms suggests the persistence of active disease.

\section{References}

1. Poiesz BJ, Ruscetti FW, Gazdar AF, Bunn PA, Minna JD, Gallo RC. Detection and isolation of type-C retroviris particles from fresh an cultured lymhocytes of a patient with cutaneous T-cell lymphoma. Proc Natl Acad Sci 1980,77:7415-7419.

2. Proietti FA, Carneiro-Proietti AB, Catalan-Soares BC, Murphy EL. Global epidemiology of HTLV-I infection and associated diseases. Oncogene 2005,24:6058-6068.

3. Edlich RF, Arnette JA, Williams FM. Global epidemic of human T-cell lymphotropic virus type I (HTLV-I). J Emerg Med 2000;18:109-119.

4. Mueller N, Okayama A, Stuver S, Tachibana N. Findings from the Miyazaki Cohort Study. J Acquir Immune Defic Syndr Hum Retrovirol 1996;13(Suppl 1):S2-S7.

5. Kitagawa T, Fujishita M, Taguchi H, Miyoshi I, Tadokoro H. Antibodies to HTLV-I in Japanese immigrants in Brazil. JAMA 1986;256:2342.

6. Gessain A, Vernant JC, Maurs L, et al. Antibodies to human T-lymphotropic virus type-1 in patients with tropical spastic paraparesis. The Lancet 1985;24:407-410.

7. Osame M. Review of WHO Kagoshima meeting and diagnostic guidelines for HAM/TSP. In: Blattner WA (Ed). Human retrovirology: HTLV. New York: Raven Press 1990;191-197.

8. Reiber $\mathrm{H}$, Felgenhauer $\mathrm{K}$. The diagnostic significance of antibody specificity indices in multiple sclerosis and herpes virus induced diseases of the nervous system. Clin Investig 1992;70:28-37.

9. Puccioni-Sohler M, Yamano Y, Rios M, et al. Differentiation of HAM/TSP from patients with multiple sclerosis infected with HTLV-1. Neurology 2007;68:206-213.

10. Umehara F, Nose H, Saito M, et al. Abnormalities of spinal magnetic resonance images implicate clinical variability in human T-cell lymphotropic vírus type I - associated myelopathy. J NeuroVirol 2007;13:260-267.

11. Godoy AJ, Kira J, Hasuo K, Goto I. Characterization of cerebral white matter lesions of HTLV-I-associated myelopathy/tropical spastic paraparesis in comparison with multiple sclerosis and collagenvasculitis: a semiquantitative MRI study. J Neurol Sci 1995;133: 102-111.

12. Kurtzke JF, Beebe GW, Nagler B, Kurland LT, Auth TL. Studies on the natural history of multiple sclerosis--8. Early prognostic features of the later course of the illness. J Chron Dis 1977;30:819-830.

13. Link H, Cruz M, Gessain A, Gout O, Thé G, Kam-Hansen S. Chronic progressive myelopathy associated with HTLV-I: oligoclonal IgG and anti-HTLV-1 IgG antibodies in cerebrospinal fluid and serum. Neurololgy 1989;39:1566-1572.

14. Reiber H, Felgenhauer K. Protein transfer at the blood cerebrospinal fluid barrier and the quantification of the humoral immune response within the central nervous system. Clin Chim Acta 1987;163:319-328.
15. Puccioni-Sohler M, Rios M, Carvalho S, et al. Diagnosis of HAM/ TSP based on CSF proviral HTLV-I DNA and HTLV-I antibody index. Neurology 2001;57:725-727.

16. Bagnato F, Butman JA, Mora CA, et al. Conventional magnetic resonance imaging features in patients with tropical spastic paraparesis. J Neurovirol 2005;11:525-534.

17. Kuroda Y, Matsui M, Yukitake M, et al. Assessment of MRI criteria for MS in Japanese MS and HAM/TSP. Neurology 1995;45:30-33.

18. Cervilla J, Cartier L, García L. [Brain and spinal cord magnetic resonance imaging in spastic paraparesis associated to human T-lymphotropic virus]. Rev Med Chil 2006;134:1010-1018.

19. Morgan DJ, Caskey MF, Abbehusen C, et al. Brain magnetic resonance imaging white matter lesions are frequent in HTLV-I carriers and do not discriminate from HAM/ TSP. AIDS Res Human Retroviruses 2007;23:1499-1503

20. Yukitake M, Takase Y, NanriY, et al. Incidence and clinical significances of human T-cell lymphotropic virus type I-associated myelopathy with T2 hyperintensity on spinal magnetic resonance images. Intern Med 2008;47:1881-1886

21. Gessain A, Gout O. Chronic myelopathy associated with human T-lymphotropic virus type I (HTLV-I). Ann Intern Med 1992;117:933-946.

22. Iwasaki Y. Pathology of chronic myelopathy associated with HTLVinfection (HAM/TSP). J Neurol Sci 1990;96:103-123.

23. Iwasaki Y, Sawada K, Aiba I, et al. Widespread active inflammatory lesions in a case of HTLV-I-associated myelopathy lasting 29 years. Acta Neuropathol 2004;108:546-551.

24. Kira J, Fujihara K, Itoyama Y, Goto I, Hasuo K. Leukoencephalopathy in HTLV-I-associated myelopathy/tropical spastic paraparesis: MRI analysis and a two year follow-up study after corticosteroid therapy. J Neurol Sci 1991;106:41-49.

25. Ogata A, Nagashima K, Tashiro K, Miyakawa A, Mikuni C.MRI-pathological correlate of brain lesions in a necropsy case of HTLV-I associated myelopathy.J Neurol Neurosurg Psychiatry 1993;56:194-196.

26. Aye MM, Matsuoka E, Moritoyo T, et al. Histopathological analysis of four autopsy cases of HTLV-I-associated myelopathy/tropical spastic paraparesis: inflammatory changes occur simultaneously in the entire central nervous system. Acta Neuropathol 2000;100:245-252.

27. Griffith C, Bagnato F, Gupta S, et al. Brain volume measurements in patients with human T- cell lymphotropic virus-1-associated tropical spastic paraparesis. J Neurovirol 2006;12:349-355.

28. Yamamoto F, Yamashita S, Yamamura A, et al. Abnormal spinal MRI findings in human T-cell lymphotropic virus type I-associated myelopathy. Clin Neurol Neurosurg 2009;111:624-628.

29. Izumo S. Neuropathology of HTLV-1-associated myelopathy (HAM/ TSP). Neuropathology 2010;30:480-485. 